\title{
Impact of increased wind power generation on subsynchronous resonance of turbine-generator units
}

\author{
Jing LI ${ }^{1}$, Xiao-Ping ZHANG ${ }^{1}$
}

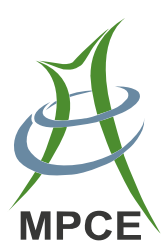

\begin{abstract}
With more and more wind power generation integrated into power grids to replace the conventional turbine-generator (T-G) units, how the subsynchronous resonance (SSR) of conventional T-G units is affected becomes an important technical issue. In this paper, a group of T-G units are interconnected with a series compensated transmission line, and some units are substituted by a nearby DFIG-based wind farm (WF). Under such circumstances, the SSR of power systems would change accordingly. This paper establishes the mathematical model to analyze the torsional interaction (TI) and the induction generator effect of the T-G units. Both eigenvalue analysis and time domain simulations demonstrate the impact of DFIG-based WF on SSR of power systems and how the control parameters of wind farms can affect the SSR.
\end{abstract}

Keywords Subsynchronous resonance (SSR), Doubly fed induction generator (DFIG), Torsional interaction (TI), Induction machine effect (IGE)

CrossCheck date: 28 September 2015

Received: 14 June 2015/Accepted: 28 September 2015/Published online: 18 February 2016

(C) The Author(s) 2016. This article is published with open access at Springerlink.com

$\triangle$ Xiao-Ping ZHANG

x.p.zhang@bham.ac.uk

Jing LI

JXL293@bham.ac.uk

1 University of Birmingham, Birmingham B15 2TT, UK

\section{Introduction}

Series capacitive compensation is widely utilized to increase the capacity of the transmission line. However, the potential risk of the series capacitive compensation is that it may cause the subsynchronous resonance (SSR). Basically, the SSR interaction is divided into three categories: torsional interaction (TI), induction generator effect (IGE) and torsional amplification (TA) $[1,2]$. The TI involves the mechanical system of a turbine-generator (T-G) unit and the electrical system. It would happen when the complement of the natural frequency of the network is close or coincides with one of the torsional frequencies of the T-G shaft system [3]. The IGE is purely an electrical phenomenon, and it depends on the generator and the electrical system. Both of the TI and IGE are related with steady state of power systems. The TA is nonlinear transient dynamics and will not be discussed in this paper. The SSR problem of the T-G units interconnected with a series compensated transmission line has been recognized for many years and extensively studied [4]. However, the increased utilization of renewable energy may affect the SSR of T-G units.

Under the pressure of environmental protection, the sources of the electrical power gradually change from conventional fossil based sources to renewable energy resources. Until now, wind energy is the most widely utilized renewable energy around the world. In Demark, the penetration of wind energy has reached $12 \%$ in 2012, providing a substantial amount of the electricity demand [5]. As the level of wind penetration increases, the dynamics of the conventional T-G units would significantly be influenced by large scale wind farms.

Due to its high capacity, low cost and flexible control, the doubly-fed induction generator (DFIG) is very popular among all the other types of wind generation [6]. In North 
America, most large wind farms employ the DFIG-base wind turbines [7]. Research papers investigated the impact of the DFIG-based wind farm on the small signal stability of power system [8-10]. The results of these publications concluded that the DFIG-based wind farms had both positive and negative effect on the electromechanical oscillations under different circumstances. On the other hand, the SSR of the DFIG-based wind farm has been studied [11, 12]. It was found that DFIG-based wind farm was very vulnerable to SSR, and the SSR was mainly attributed to the IGE instead of the TI. This conclusion was also confirmed by the SSR phenomenon in practical wind farms [13]. Reference [14] presented the procedures to study the SSR in wind integrated power systems. Moreover, the DFIG-based wind farm was utilized to damp the torsional oscillations of the conventional T-G units [6, 7]. However, the above publications have not studied that the impacts of the DFIG-based wind farm on the SSR of conventional T-G units.

Thus, the contribution of this paper is to systematically investigate the impacts of the DFIG-based wind farm on the SSR of T-G units. The test benchmark is modified from the IEEE first benchmark model. The detailed model is established for the test system. The eigenvalue analysis and time domain simulation are conducted to examine the influence of wind farm on both TI and IGE of the T-G unit and how the control parameters of wind farms can affect the SSR.

This paper is organized as follows. In Section 2, the details of the studied test benchmark are introduced. Then, the detailed models for the T-G units, the DFIG-based wind turbine and the transmission line are presented in Section 3. Section 4 describes the eigenvalue analysis and time domain simulations of the studied system. The results of eigenvalue analysis and time domain simulations for both TI and IGE are demonstrated in Section 5 and 6. Section 7 summarizes this paper.

\section{Test benchmark}

To evaluate the subsynchronous resonance of the T-G unit with increased wind energy penetration, the IEEE first benchmark model (FBM) is modified as Fig. 1. GEN 1 is the original generator from the IEEE FBM, the power factor and the output power (803.16 MW) remain the same. GEN 2 is aggregated by several 75 MW synchronous generators, and these generators are assumed to be exempt of SSR due to their small capacity. The wind farm is aggregated by a large number of $1.5 \mathrm{MW}, 0.69 \mathrm{kV}$ DFIGbased wind turbines. The overall output power of GEN 2 and wind farm is $750 \mathrm{MW}$. The original series compensated transmission line in the IEEE FBM is doubled to

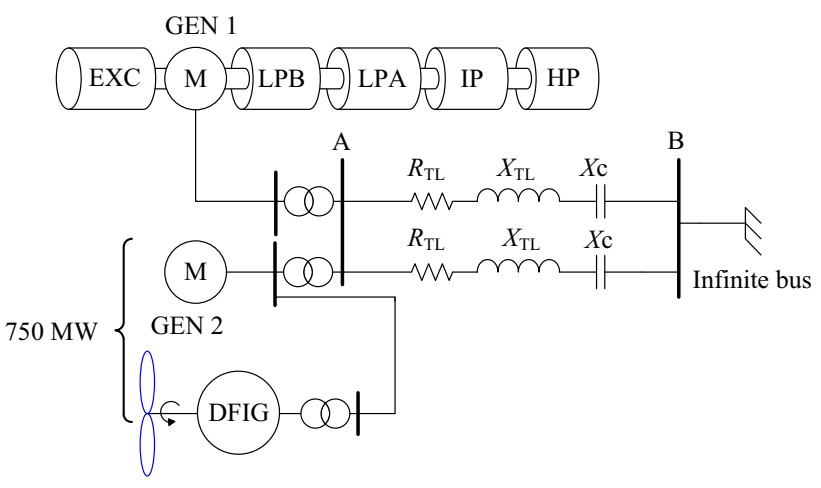

Fig. 1 Test benchmark

increase the transmission capacity, and GEN 1, GEN 2 and the wind farm are connected with an infinite bus through these transmission lines.

The shaft system of the GEN 1 consists of six torsional masses: a high-pressure turbine section (HP), an intermediate-pressure turbine section (IP), two low-pressure turbine section (LPA and LPB), a rotor of generator (GEN) and a rotating exciter (EXC). Since six masses are considered in the shaft system, there are six modes of oscillation, named from Mode 0 to Mode 5. The Mode 0 represents the oscillation of the entire six masses against the power system, and it is often considered in system stability studies [3]. The other five modes are the torsional oscillation modes, and their mode shapes can be found in [15]. The compensation level of the transmission line tuned to excite Mode 2. Mode 2 has a natural frequency of $21.21 \mathrm{~Hz}$, and it includes two polarity reversals according to the mode shapes. One polarity reversal happens between the LPA and LPB section, and the other one happens between the GEN and EXC section. So, in the time domain simulation, the excited oscillation of Mode 2 can be observed through the torsional response of LPA-LPB and GEN-EXC. The shaft system of the generators in GEN 2 is modeled as a lumped mass.

In this paper, the wind farm is supposed to replace conventional generators in GEN 2 gradually. The number of wind turbines in the aggregated wind farm will change to demonstrate the scenarios with different penetration level of wind energy. However, the overall power generated by GEN 2 and the DFIG-based wind farm will be kept unchanged at $750 \mathrm{MW}$. The power factor and output power of GEN 1 will be the same as in the IEEE FBM.

\section{System modeling}

The benchmark system has been introduced in previous part. In this part, every component of the benchmark system will be modeled separately for eigenvalue analysis. 


\subsection{Turbine-generator unit}

1) Shaft system

The shaft system of GEN 1 comprises six torsional masses. When the mechanical damping is assumed to be zero, the motion equations of the shaft system are as follows.

$\frac{\mathrm{d} \delta_{i}}{\mathrm{~d} t}=\omega_{\mathrm{b}} \Delta \omega_{i}$

$\frac{\mathrm{d} \Delta \omega_{i}}{\mathrm{~d} t}=\frac{1}{2 H_{i}}\left[T_{i}+K_{i-1, i}\left(\delta_{i-1}-\delta_{i}\right)-K_{i, i+1}\left(\delta_{i}-\delta_{i+1}\right)\right]$

$T_{5}=-T_{\mathrm{e}}$

where $i=1,2, \ldots, 6 ; \delta_{i}$ is the angular position of mass $i$; $\Delta \omega_{i}$ is the speed deviation of mass $i ; K_{i-1, i}$ and $K_{i, i+1}$ are the shaft stiffness; $T_{i}$ is the mechanical torques of each turbine section; $T_{\mathrm{e}}$ is the electromagnetic torque of generator; $H_{i}$ is the inertia constant of each turbine section; $K_{0,1}=K_{6,7}=0 ; \omega_{\mathrm{b}}$ is the base speed (377 $\left.\mathrm{rad} / \mathrm{s}\right)$.

The shaft system of GEN 2 only includes one lumped mass, and it also can be demonstrated by the above model accordingly.

2) Synchronous machine

As for the SSR analysis, the model of the synchronous machine (SM) often includes two rotor circuits in the $d$ and $q$ axis, respectively [4]. Both GEN 1 and GEN 2 can be demonstrated by the following,

$\dot{\boldsymbol{x}}_{\mathrm{sm}}=f_{\mathrm{sm}}\left(\boldsymbol{x}_{\mathrm{sm}}, \boldsymbol{z}_{\mathrm{sm}}, \boldsymbol{u}_{\mathrm{sm}}\right)$

where $\boldsymbol{x}_{\mathrm{sm}}=\left[\psi_{d}, \psi_{\mathrm{fd}}, \psi_{1 d}, \psi_{q}, \psi_{1 q}, \psi_{2 q}\right]^{\mathrm{T}} ; \boldsymbol{z}_{\mathrm{sm}}=\left[\omega_{5}\right]^{\mathrm{T}}$; $\boldsymbol{u}_{\mathrm{sm}}=\left[v_{d}, v_{q}\right]^{\mathrm{T}} ; v_{d}$ and $v_{q}$ are the $d$ and $q$ axis voltages of the stator, respectively; $\psi_{d}$ and $\psi_{q}$ are the $d$ and $q$ axis linkages of the stator, respectively; $\psi_{\mathrm{fd}}$ is the linkage of the field winding; $\psi_{1 d}$ and $\psi_{1 q}$ are the linkages of the 1st $d$ and $q$ axis amortisseur, respectively; $\psi_{2 q}$ is the linkage of the 2nd $q$ axis amortisseur; $\omega_{5}$ is the rotor angle speed.

\subsection{DFIG-based wind turbine}

The model of the DFIG-based wind turbine includes the drive train, the induction machine, the DC-link capacitor,

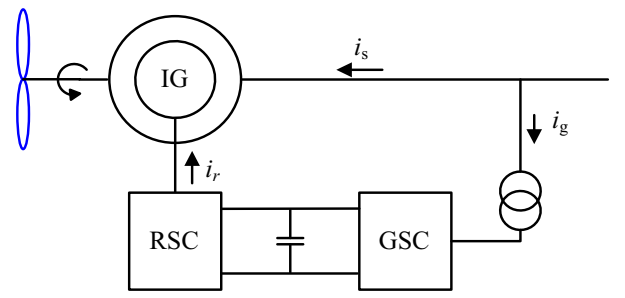

Fig. 2 Structure of DFIG-based wind turbine the rotor side and grid side converter, as shown in Fig. 2. In the following, the model of each part will be introduced separately.

1) Drive train

The drive train includes wind turbine, gearbox, shafts and other mechanical components, and it is usually represented by a two-mass model [16].

2) Induction generator

In general, the generator of DFIG is a wound rotor induction machine. The model of the induction generator, in the $d-q$ reference, is given by [16].

$\dot{\boldsymbol{x}}=f(\boldsymbol{x}, \boldsymbol{z}, \boldsymbol{u})$

where $\boldsymbol{x}=\left[i_{d \mathrm{~s}}, i_{q \mathrm{~s}}, E_{d}^{\prime}, E_{q}^{\prime}\right]^{\mathrm{T}} ; \boldsymbol{z}=\left[v_{d \mathrm{r}}, v_{q \mathrm{r}}\right]^{\mathrm{T}} ; \boldsymbol{u}=\left[v_{d \mathrm{~s}},-\right.$ $v_{q \mathrm{~s}} \mathrm{~S}^{\mathrm{T}} ; E^{\prime}{ }_{d}$ and $E_{q}^{\prime}{ }_{q}$ are the $d$ and $q$ axis voltages behind the transient reactance, respectively; $i_{d \mathrm{~s}}$ and $i_{q \mathrm{~s}}$ are the $d$ and $q$ axis stator currents, respectively; $v_{d \mathrm{~s}}$ and $v_{q \mathrm{~s}}$ are the $d$ and $q$ axis stator voltages, respectively; $v_{d \mathrm{r}}$ and $v_{q \mathrm{r}}$ are the $d$ and $q$ axis rotor voltages.

3) DC-link capacitor

The active power is fed back from the stator to the rotor through the DC-link capacitor. The energy is balanced in this capacitor, so the following equations can be obtained,

$C v_{\mathrm{DC}} \frac{\mathrm{d} v_{\mathrm{DC}}}{\mathrm{d} t}=v_{d \mathrm{~g}} i_{d \mathrm{~g}}+v_{q \mathrm{~g}} i_{q \mathrm{~g}}-\left(v_{d \mathrm{r}} i_{d \mathrm{r}}+v_{q \mathrm{r}} i_{q \mathrm{r}}\right)$

where $v_{d \mathrm{~g}}$ and $v_{q \mathrm{~g}}$ are the $d$ and $q$ axis voltages of the gridside converter; $i_{d \mathrm{~g}}$ and $i_{q \mathrm{~g}}$ are the $d$ and $q$ axis currents of the grid-side converter; $v_{d \mathrm{r}}$ and $v_{q \mathrm{r}}$ are the $d$ and $q$ axis rotor voltages; $i_{d \mathrm{r}}$ and $i_{q \mathrm{r}}$ are the $\mathrm{d}$ and $\mathrm{q}$ axis rotor currents; $v_{\mathrm{DC}}$ is the DC capacitor voltage; $C$ is the capacitance of the DC capacitor.

4) Rotor and grid side converters

The objective of the rotor side converter is to control the electromagnetic torque and the reactive power of the DFIG. The control block diagram of the rotor-side converter is shown as Fig. 3.

The GSC is designed to maintain the DC link voltage and control the reactive power of the terminal. The control block diagram of the grid-side converter is shown as Fig. 4.

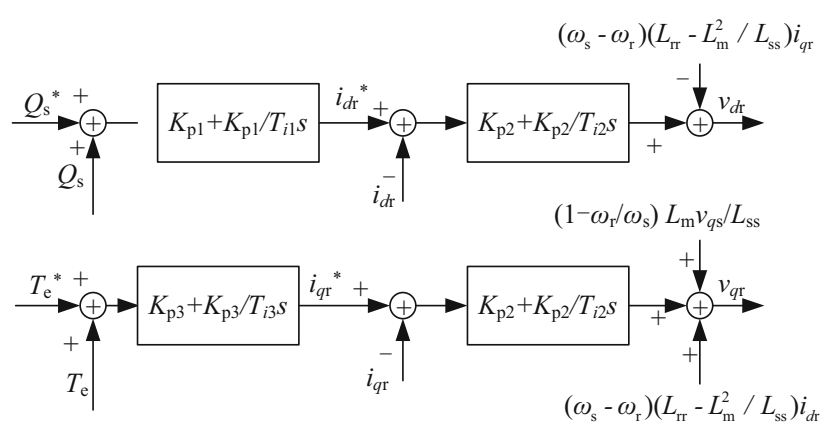

Fig. 3 Control block diagram of rotor-side converter 


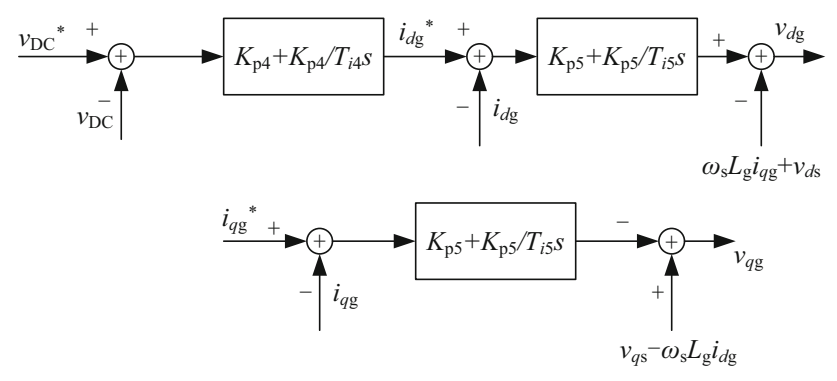

Fig. 4 Control block diagram of grid-side converter

\subsection{Transmission line}

In the same $d-q$ axis reference frame as the SM, the model of the series compensated transmission line can be described by

$$
\begin{aligned}
& \frac{1}{\omega_{\mathrm{b}}} \frac{\mathrm{d} v_{\mathrm{c} d}}{\mathrm{~d} t}-\omega_{\mathrm{r}} v_{\mathrm{c} q}=X_{\mathrm{c}} i_{d \mathrm{~L}} \\
& \frac{1}{\omega_{\mathrm{b}}} \frac{\mathrm{d} v_{\mathrm{c} q}}{\mathrm{~d} t}+\omega_{\mathrm{r}} v_{\mathrm{c} d}=X_{\mathrm{c}} i_{q \mathrm{~L}} \\
& R_{\mathrm{TL}} i_{d \mathrm{~L}}-\omega_{\mathrm{r}} X_{\mathrm{TL}} i_{q \mathrm{~L}}+\frac{X_{\mathrm{TL}}}{\omega_{\mathrm{b}}} \frac{\mathrm{d} i_{d \mathrm{~L}}}{\mathrm{~d} t}+v_{\mathrm{c} d}=v_{d}-v_{1 d} \\
& R_{\mathrm{TL}} i_{q \mathrm{~L}}+\omega_{\mathrm{r}} X_{\mathrm{TL}} i_{d \mathrm{~L}}+\frac{X_{\mathrm{TL}}}{\omega_{\mathrm{b}}} \frac{\mathrm{d} i_{q \mathrm{~L}}}{\mathrm{~d} t}+v_{\mathrm{c} q}=v_{q}-v_{1 q}
\end{aligned}
$$

where $v_{\mathrm{c} d}$ and $v_{\mathrm{c} q}$ are the $d$ and $q$ axis voltages across the compensation capacitor; $v_{1 d}$ and $v_{1 q}$ are the $d$ and $q$ axis voltages of the infinite bus; $i_{d \mathrm{~L}}$ and $i_{q \mathrm{~L}}$ are the $d$ and $q$ axis currents through the transmission line; $X_{\mathrm{c}}$ is the reactance of the compensation capacitor; $X_{\mathrm{TL}}$ is the combined reactance of the transmission line; $R_{\mathrm{TL}}$ the combined resistance of the transmission line.

\section{Eigenvalue analysis and time domain simulation}

To evaluate the impact of increased wind energy on the SSR of the test benchmark, the eigenvalue analysis and time domain simulation are conducted in the following two cases.

Case 1: The test benchmark as Fig. 1 without the wind farm. The number of synchronous generators in GEN 2 is 10 , and the output power of each one is $75 \mathrm{MW}$

Case 2: The test benchmark as Fig. 1. A certain number of power generators in GEN 2 are substituted by a DFIGbased wind farm with equivalent capacity.

\subsection{Eigenvalue analysis}

The linearized dynamic equations of GEN 1, GEN 2 and the DFIG-based wind farm are derived from the mathematical model in previous part at an operating point. These linearized equations can be written in state space form as

$\Delta \dot{X}_{1}=A_{1} \Delta X_{1}+B_{1} \Delta U$

where $\Delta X_{1}=\left[\Delta X_{\mathrm{GEN} 1}, \Delta X_{\mathrm{GEN} 2}, \Delta X_{\mathrm{WT}}\right]^{\mathrm{T}} ; \Delta X_{\mathrm{GEN} 1}$ is the state variables of GEN 1 , it includes the rotating speeds of 6 masses, 6 relative angles between the masses and 6 flux linkages of the synchronous machine; $\Delta X_{\mathrm{GEN} 2}$ is the state variables of GEN 2, and it consists of the rotating speed of the lumped mass, the rotor angle and 6 flux linkages of the synchronous machine. $\Delta X_{\mathrm{WT}}$ is the state variables of DFIG-based wind farm, and it contains 3 drive train states, 4 states of the induction generator, 4 controller states of the rotor-side controller, the voltage of the DC-link capacitor, 3 controller states of the grid-side converter and 2 states for the currents of the grid-side controller. The 2 inputs in $\Delta U$ are the $d$ and $q$ axis voltages of Bus A.

The linearized equation of the series compensated network can be demonstrated by

$\Delta \dot{X}_{\text {net }}=A_{\text {net }} \Delta X_{\text {net }}+C_{1} \Delta X_{1}$

$\Delta U=C_{2} \Delta X_{1}+C_{3} \Delta X_{\text {net }}+D_{1} \Delta \dot{X}_{1}$

The state variable vector $\Delta X_{\text {net }}$ includes the $d$ and $q$ axis voltages of compensation capacitor.

The inputs in (11) can be eliminated by (13). Then, the model of the test benchmark can be represented by a complete state space equation as

$\Delta \dot{X}=A \Delta X$

where $\Delta X=\left[\Delta X_{1}, \Delta X_{\text {net }}\right]^{\mathrm{T}}$.

Based on (14), the eigenvalues of Case 2 can be calculated according to the operating point and the parameters in Appendix A. As for Case 1, the eigenvalues can be obtained after removing the state variables of wind farm in $\Delta X_{1}$.

\subsection{Time domain simulation}

To verify the eigenvalue analysis, the simulation platform for Case 1 and Case 2 are both established in PSCAD/ EMTDC. In both cases, dynamics of the excitation and governor systems in GEN 1 and GEN 2 are not included in this simulation. The compensation level is tuned to excite the second torsional mode. During the simulation, a threephase fault happens at bus $\mathrm{B}$, and the fault duration is $75 \mathrm{~ms}$ (four and a half cycles at $60 \mathrm{~Hz}$ ) [17]. The torsional oscillation of Mode 2 can be observed through the responses of LPA-LPB and GEN-EXC. As shown in Fig. 5a, the torsional responses of LPA-LPB and GENEXC exhibit severe instability after the three phase fault at Bus B. 


\section{Results of torsional interaction}

In this part, the DFIG-based wind farm will replace a certain number of generators in GEN 2 with equivalent capacity. The impact of this replacement on the torsional interaction of GEN 1 will be investigated.

In the test benchmark, the torsional oscillations of GEN 1 unit mainly depend on the compensation level of the transmission line and the dynamics of the wind farm. To
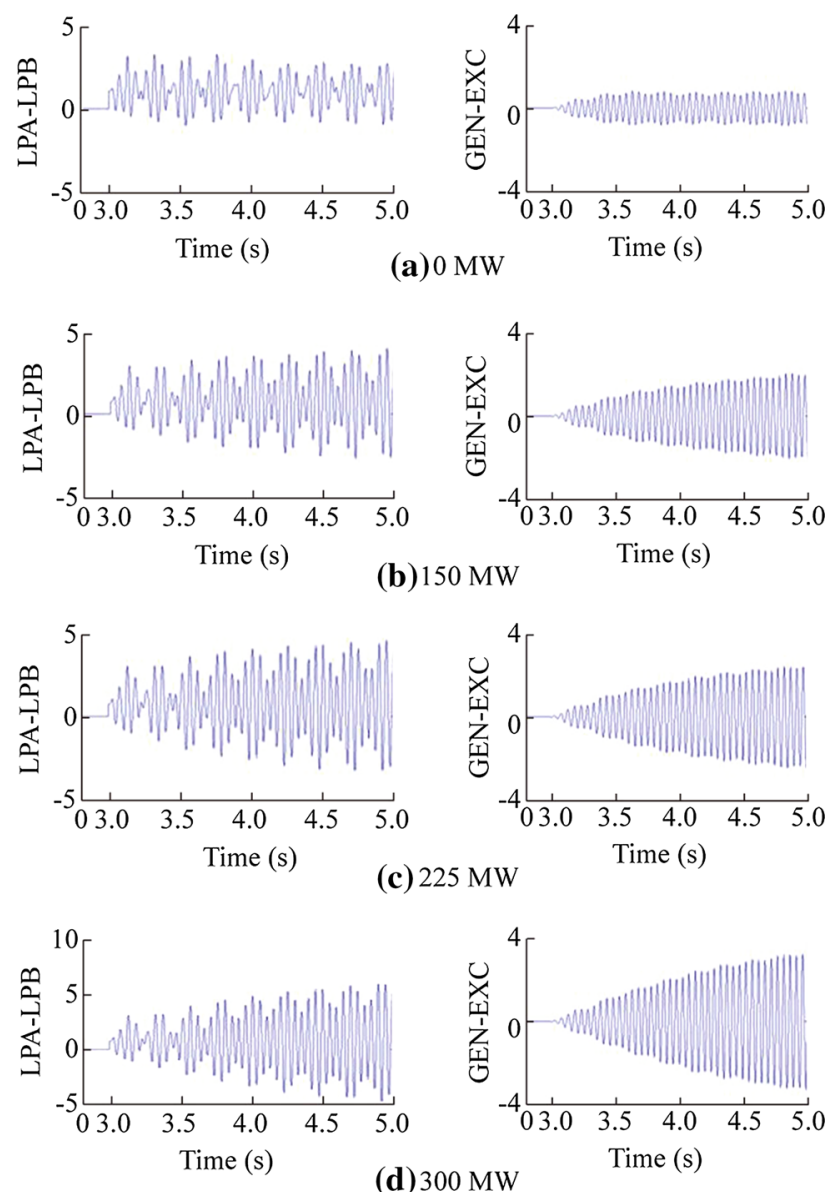

Fig. 5 Torsional response of Mode 2 excite the same mode of torsional oscillation, the compensation level remains the same in this part. The dynamics of the wind farm are attributed to three major factors: the scale of the wind farm, the control parameters and the operating point of wind generators. In the following studies, with the changes of these three factors, the effect of the wind farm on the torsional interaction of the GEN 1 is studied.

\subsection{Impact of wind farm scale}

The torsional mode of GEN 1 may change when some generators in GEN 2 is replaced by the increased wind farm. Initially, the DFIG-based wind farm is supposed to contain 100 wind turbines, and the output power of each wind turbine is $1.5 \mathrm{MW}$. Consequently, two $75 \mathrm{MW}$ power generators in GEN 2 stop to produce power. Then, the number of DFIG-based wind turbines increases from 100 to 200 , and the number of replaced generators in GEN 2 increases from 2 to 4 .

Fig. 5a shows the torsional torques of LPA-LPB and GEN-EXC in Case 1 after Mode 2 is excited by the fault. Fig. 5b-d show the torsional responses of Mode 2 in Case 2 under different wind farm scale. According to these simulations, it is concluded that the replacement of conventional power plants by wind energy generation will have a negative effect on the damping of TI. As more conventional power plants are substituted by the DFIG-based wind farm, the torsional responses of LPA-LPB and GEN-EXC are more severe, which means the damping of TI becomes even worse. The eigenvalues of Mode 2 under different wind farm scales listed in Table 1 can also confirm this observation.

\subsection{Impact of DFIG converter control}

In this section, the impact of the DFIG converter control on the TI will be investigated. The number of the DFIGbased wind turbines is fixed at 100 , and the output power of each wind turbine is still 1.5 MW.

Table 1 Torsional Mode 2 under variable wind farm scale

\begin{tabular}{llll}
\hline Wind farmscale $(\mathrm{MW})$ & Eigenvalue (Mode 2) & Damping $(\%)$ & Frequency $(\mathrm{Hz})$ \\
\hline 0 & $0.29 \pm 127.95 i$ & -0.227 & 20.364 \\
150 & $0.56 \pm 127.84 i$ & -0.438 & 20.351 \\
225 & $0.71 \pm 127.17 i$ & -0.558 & 20.240 \\
300 & $0.78 \pm 127.19 i$ & -0.613 & 20.243 \\
375 & $0.82 \pm 127.21 i$ & -0.645 & 20.246 \\
450 & $0.85 \pm 127.23 i$ & -0.668 & 20.249 \\
525 & $0.87 \pm 127.25 i$ & -0.684 & 20.252 \\
600 & $0.89 \pm 127.26 i$ & -0.699 & 20.254 \\
\hline
\end{tabular}


It is found that the inner current control loop of RSC has a significant impact on the TI of GEN 1. The control loop of RSC is shown as Fig. 3, and $K_{\mathrm{p} 2}$ is the proportional gain of the inner controller. To evaluate the effect of $K_{\mathrm{p} 2}$, the eigenvalues of Mode 2 with different $K_{\mathrm{p} 2}$ are listed in Table 2. As $K_{\mathrm{p} 2}$ decreases, the damping of Mode 2 will increase correspondingly. This trend can also be verified by the time domain simulations as shown in Fig. 6.

\subsection{Impact of operating points}

Under different wind speeds, the DFIG-based wind turbines will work at different operating points. Due to the large slip range of DFIG, the dynamics of the wind farm is dependent on the operating point, and it may also affect the torsional oscillations of GEN 1. In this paper, the relationship between the wind speed and the active power generated by DFIG is demonstrated in Table 3. As the wind speed increases, the DFIG operates from sub-synchronous speed to super-synchronous speed.

To exclude the effect of the scale of wind farm, the total number of wind turbines remains 100, and 2 generators in GEN 2 will be removed. In the following study, the output power of each DFIG varies from 0.75 to $1.5 \mathrm{MW}$. The torsional responses of LPA-LPB and GEN-EXC under different operating points are shown in Fig. 7. Both eigenvalue analysis (Table 4) and time domain simulation demonstrate that the torsional interaction of the T-G unit have even worse damping as the DFIGs in the wind farm operates from the sub-synchronous speed to the supersynchronous speed.

\section{Results of induction generator effect}

For this part of study, the induction machine effect of the test benchmark is analyzed when some generators in GEN 2 are substituted by a DFIG-based wind farm. To focus on the IGE, the torsional dynamics of GEN 1 are disabled in both eigenvalue analysis and time domain simulation. The resistance of the series compensated transmission line $R_{\mathrm{TL}}$ is reduced to 0.00645 to excite the IGE. The eigenvalues of the network mode [3] and the
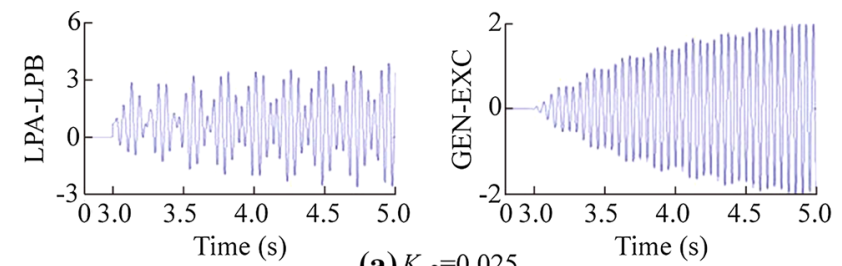

(a) $K_{\mathrm{p} 2}=0.025$
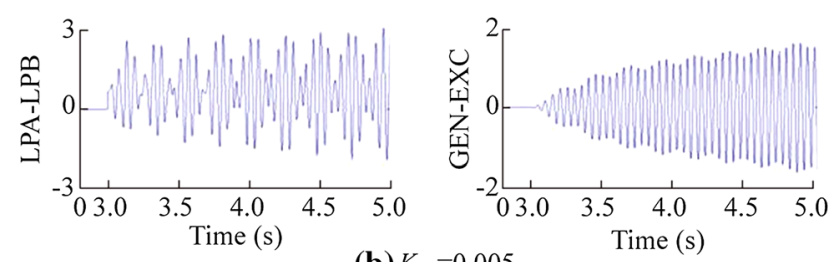

(b) $K_{\mathrm{p} 2}=0.005$

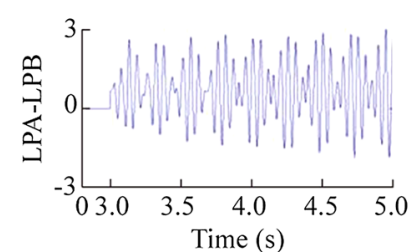

(c) $K_{\mathrm{p} 2}=0.001$

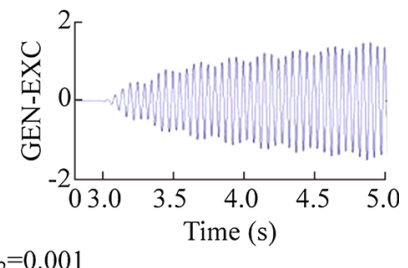

Fig. 6 Torsional response of Mode 2 under different $K_{\mathrm{p} 2}$

Table 3 Operating point of a DFIG-based wind turbine

\begin{tabular}{lll}
\hline Speed type & Wind speed $(\mathrm{m} / \mathrm{s})$ & Output power $(\mathrm{MW})$ \\
\hline Sub-synchronous speed & 8.654 & 0.75 \\
& 9.525 & 1 \\
Super-synchronous speed & 10.260 & 1.25 \\
& 10.903 & 1.5 \\
\hline
\end{tabular}

dynamic response of the series capacitor voltage after the fault can demonstrate the subsychronous frequency oscillation of the network (i.e. IGE). In the time domain simulations, the fault condition is the same as that in the study of TI. The compensation level of the series compensated transmission line initially is $74.2 \%$ as in the IEEE FBM.

\subsection{Impact of compensation level}

IGE is a purely electrical phenomenon, and it is largely dependent on the compensation level. As the compensation

Table 2 Torsional Mode 2 under different control parameters

\begin{tabular}{llll}
\hline Control parameter $K_{\mathrm{p} 2}$ & Eigenvalue (Mode 2) & Damping $(\%)$ & Frequency $(\mathrm{Hz})$ \\
\hline 0.025 & $0.56 \pm 127.84 i$ & -0.438 & 20.346 \\
0.015 & $0.51 \pm 127.79 i$ & -0.399 & 20.338 \\
0.005 & $0.45 \pm 127.77 i$ & -0.352 & 20.335 \\
0.0025 & $0.41 \pm 127.76 i$ & -0.321 & 20.334 \\
0.001 & $0.39 \pm 127.76 i$ & -0.305 & 20.334 \\
\hline
\end{tabular}


level changes, the influence of the wind farm on the IGE may also be different.

In this section, the impact of the compensation level on the IGE of the test benchmark is investigated. As for both Case 1 and Case 2, the compensation level decreases from $74.2 \%$ to $10 \%$. In Case 2, two 75 MW generators in GEN 2 are substituted by a hundred 1.5 MW DFIG-based wind turbines. Initially, the control parameter $K_{\mathrm{p} 2}$ is set to 0.05 . The dynamic responses of the capacitor voltages in both Case 1 and Cass 2 under different compensation level are shown in Fig. 8.

The simulation results indicate that the DFIG-based wind farm has a negative impact on the IGE at the
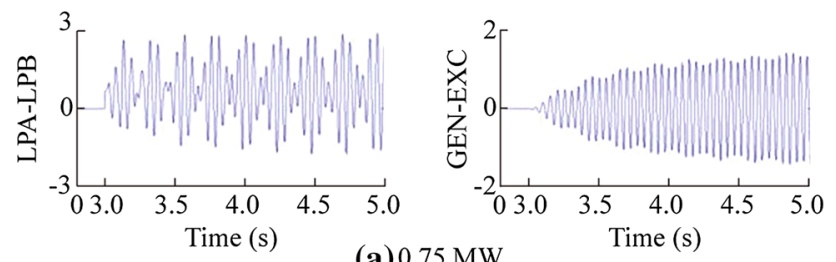

(a) $0.75 \mathrm{MW}$
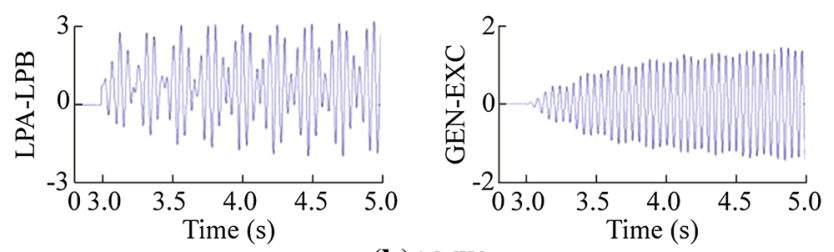

(b) $1 \mathrm{MW}$
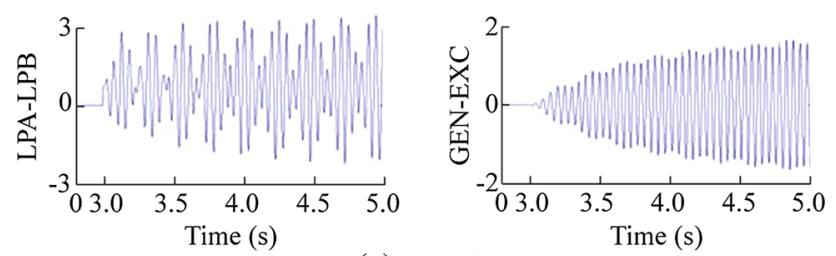

(c) $1.25 \mathrm{MW}$
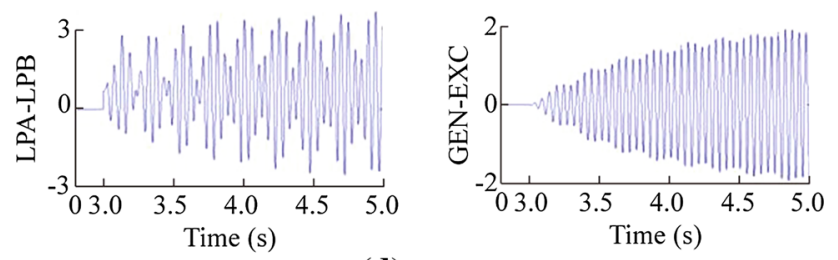

(d) $1.5 \mathrm{MW}$

Fig. 7 Torsional response of Mode 2 under different operating point compensation levels of $74.2 \%$ and $70 \%$, while the positive influence will manifest as the compensation level decreases. So the impact of the DFIG-based wind farm on the IGE of the T-G unit depends on the compensation level of the series compensated transmission line.

Then, the proportional gain $K_{\mathrm{p} 2}$ decreases from 0.05 to 0.001. From Figs. 8 and 9, it is concluded that the damping of network mode improves with the decreased $K_{\mathrm{p} 2}$. However, this does not change the trend of the above conclusion. All the eigenvalues for both Case 1 and Case 2 under different compensation level are summarized in Fig. 10.
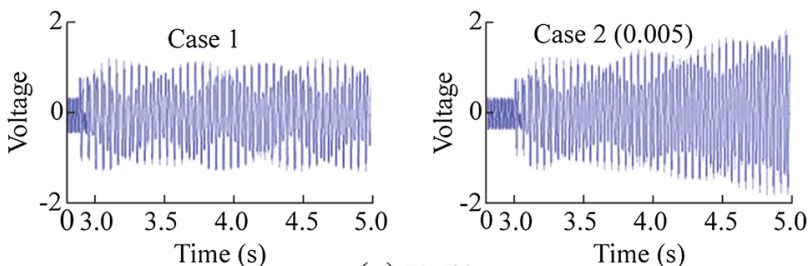

(a) $72.4 \%$
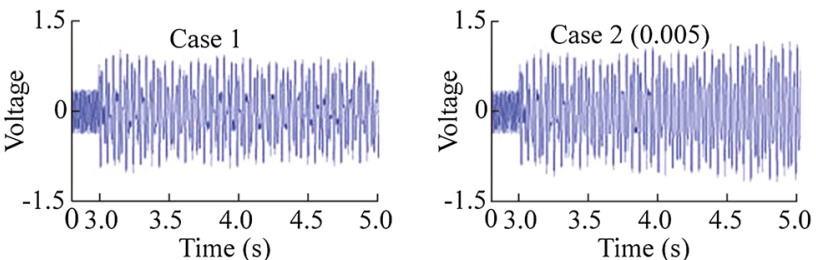

(b) $70 \%$
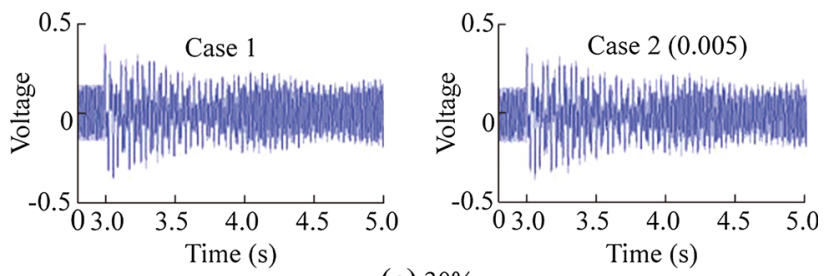

(c) $30 \%$
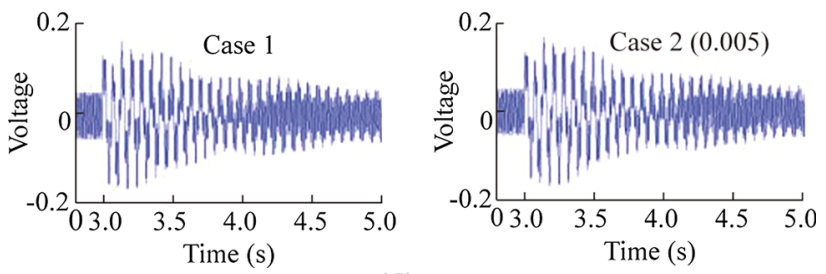

(d) $10 \%$

Fig. 8 Dynamic response of series capacitor voltage $\left(K_{\mathrm{p} 2}=0.005\right)$

Table 4 Torsional Mode 2 under variable operating point

\begin{tabular}{llll}
\hline Operating point $(\mathrm{MW})$ & Eigenvalue (Mode 2) & Damping (\%) & Frequency $(\mathrm{Hz})$ \\
\hline 0.75 & $0.42 \pm 127.46 i$ & -0.330 & 20.286 \\
1 & $0.46 \pm 126.59 i$ & -0.363 & 20.147 \\
1.25 & $0.50 \pm 127.72 i$ & -0.391 & 20.327 \\
1.5 & $0.56 \pm 127.84 i$ & -0.438 & 20.346 \\
\hline
\end{tabular}



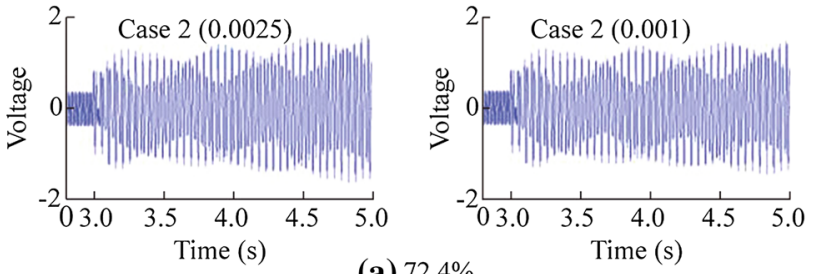

(a) $72.4 \%$
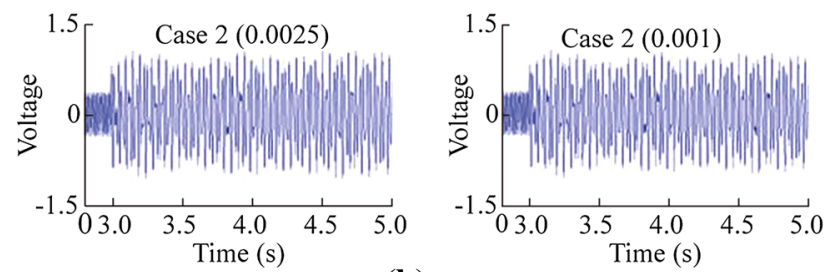

(b) $70 \%$
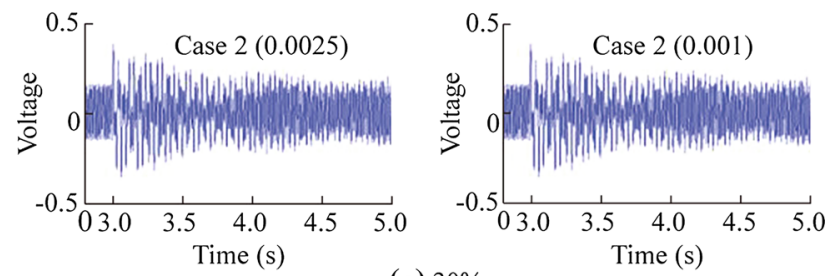

(c) $30 \%$
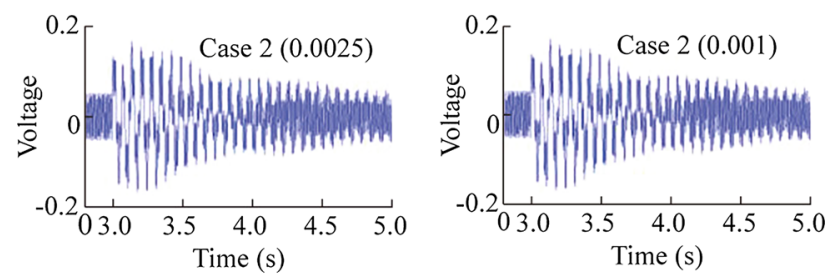

(d) $10 \%$

Fig. 9 Dynamic response of series capacitor $\left(K_{\mathrm{p} 2}=0.0025 / 0.001\right)$

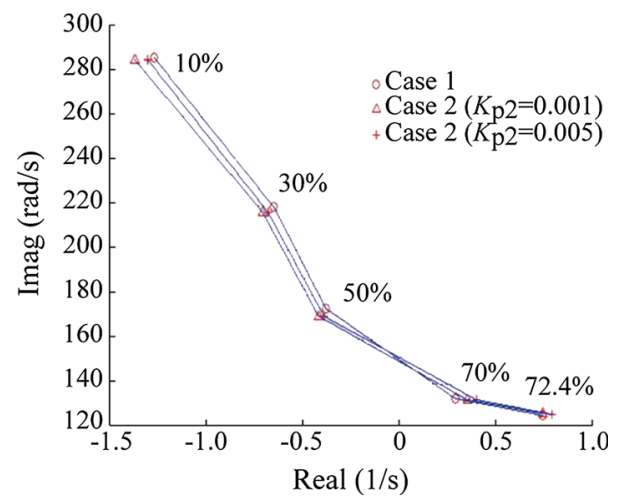

Fig. 10 Network resonance mode under different compensation level with various control parameters

\subsection{Impact of wind farm scale}

In this section, the impact of increased wind farm on the IGE of test benchmark will be investigated. In Case 2, there are 100 DFIG-based wind turbines in the wind farm at the
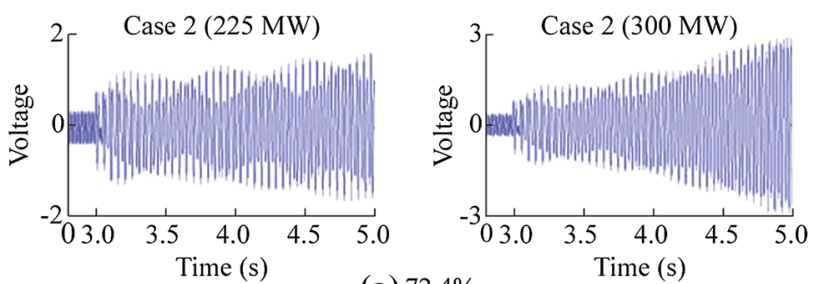

(a) $72.4 \%$
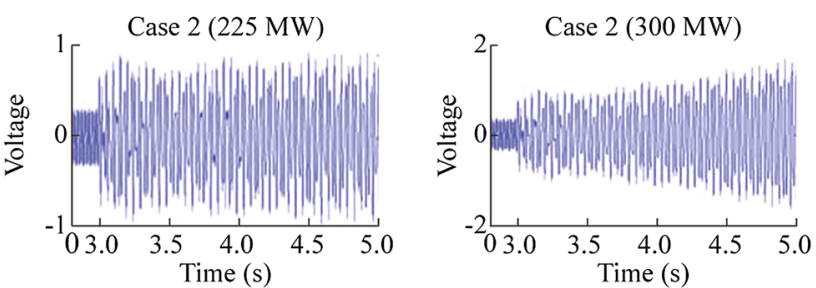

(b) $70 \%$
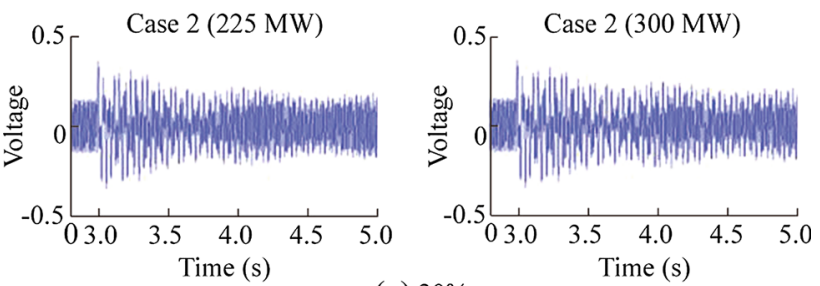

(c) $30 \%$
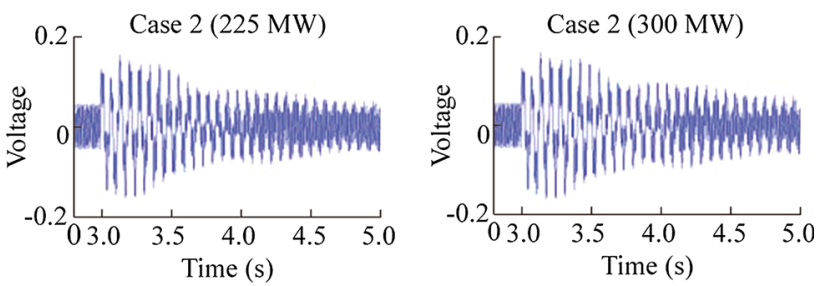

(d) $10 \%$

Fig. 11 Dynamic response of series capacitor voltage

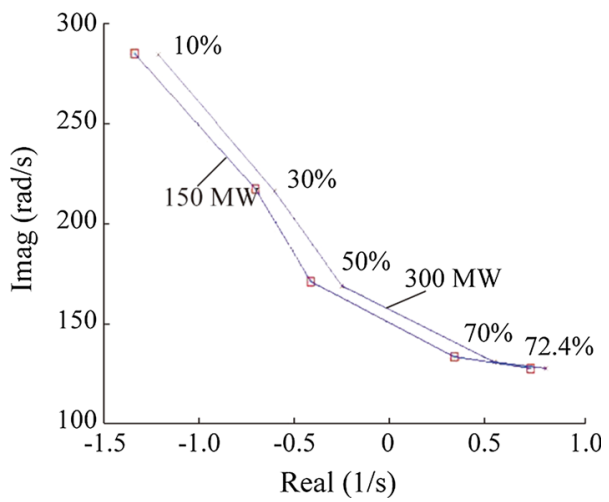

Fig. 12 Network resonance mode under different compensation level for Case 2 with increased wind farm scale

beginning, and the output power of each wind turbine is 1.5 MW. Then, the number of wind turbines increases from 100 to 200, and the number of replaced generators in GEN 2 increases from 2 to 4 accordingly. During the above process, the control parameter $K_{\mathrm{p} 2}$ is fixed at 0.0025 . 
Figures 9 and 11 show the responses of the series capacitor voltage with increased wind farm scale. As the wind farm scale increases from 150 to $300 \mathrm{MW}$, the damping of the network mode reduces at all the compensation levels. This means the damping of IGE will be worse as more conventional generators are replaced by DFIGbased wind farm. The eigenvalues of network mode shown in Fig. 12 can also support this conclusion.

\section{Conclusions}

This paper has conducted a SSR analysis of the T-G unit when some conventional power plants were replaced by a DFIG-based wind farm. The influences of the wind farm on the TI and IGE of the T-G unit have been investigated. To evaluate the impacts, the IEEE FBM has been modified. Then, the eigenvalue analysis has been conducted based on the detailed mathematical model of the test benchmark. The results of the eigenvalue analysis have also been verified through the time domain simulations in the PSCAD/ EMTDC.

The replacement of conventional power plants by the DFIG-based wind farm has a negative effect on the TI of the T-G unit, and it can be summarized as follows.

1) The larger the wind farm capacity, the less damping of the torsional oscillation.

2) The inner current controller of RSC have a significant impact on TI. The smaller proportional gain of the controller, the better damping of the torsional oscillation.

3) The higher the rotating speed of the DFIG, the less damping of the torsional oscillation.

On the other hand, the impact of replacement on the IGE depends on the compensation level. When the compensation level is high and the system is excited to lose its stability, the DFIG-based wind farm makes the oscillation even worse. When the compensation level is low enough to maintain the stability under the fault, the wind farm improves the damping of the oscillation. Meanwhile, the IGE will be worse if more conventional power plants are substituted by DFIG-based wind farms.

Open Access This article is distributed under the terms of the Creative Commons Attribution 4.0 International License (http:// creativecommons.org/licenses/by/4.0/), which permits unrestricted use, distribution, and reproduction in any medium, provided you give appropriate credit to the original author(s) and the source, provide a link to the Creative Commons license, and indicate if changes were made.

\section{Appendix A}

1. Parameters of the First IEEE Benchmark System
1) Per-unit base values

$P_{\mathrm{b}}=892.4 \mathrm{MVA}, V_{\mathrm{b}}=539 \mathrm{kV}, \omega_{\mathrm{b}}=376.99 \mathrm{rad} / \mathrm{s}$

2) Multi-mass of turbine-generator unit

Inertia constant $(\mathrm{s}): H_{1}=0.092897, H_{2}=0.155589$, $H_{3}=0.858670, H_{4}=0.884215, H_{5}=0.868495$

Spring constants (torque/rad): $K_{12}=19.303, K_{23}=$ $34.929, K_{34}=52.038, K_{45}=70.858, K_{56}=2.822$

3) Generator parameters

Generator power output $P_{\mathrm{o}}=0.9$

Generator power factor $f_{\mathrm{p}}=0.9$ (lagging)

Stator armature resistance $R_{\mathrm{a}}=0$

$d$-axis: $\quad X_{l}=0.13, \quad X_{\mathrm{ad}}=1.66, \quad X_{\mathrm{f} d}=0.04, \quad X_{1 d}=$ $0.00573, R_{\mathrm{f} d}=0.00105, R_{1 d}=0.003713$

$q$-axis: $X_{1}=0.13, X_{\mathrm{a} q}=1.58, X_{1 q}=0.1045, X_{2 q}=$ $0.2449, R_{1 q}=0.005257, R_{2 q}=0.01819$

4) Transmission line

$R_{\mathrm{TL}}=0.0187, X_{\mathrm{TL}}=0.7, X_{\mathrm{c}}=0.371$

2. Parameters of a single generator in GEN 2

Rated power: 89.24 MVA

Rated voltage: $15.01 \mathrm{kV}$

Stator armature resistance: 0

$d$-axis: $\quad X_{1}=0.13, \quad X_{\mathrm{a} d}=1.66, \quad X_{\mathrm{f} d}=0.04, \quad X_{1 d}=$ $0.00573, R_{\mathrm{f} d}=0.00105, R_{1 d}=0.003713$

$q$-axis: $X_{1}=0.13, X_{\mathrm{a} q}=1.58, X_{1 q}=0.1045, X_{2 q}=$ $0.2449, R_{1 q}=0.005257, R_{2 q}=0.01819$

3. Parameters of a single DFIG-based wind turbine

1) Per unit system

$S_{\mathrm{b}}=2.2 \mathrm{MW}, V_{\mathrm{b}}=0.69 \mathrm{kV}$

2) Wind turbine

$V_{\mathrm{w}}=10.903 \mathrm{~m} / \mathrm{s}, \quad C_{\mathrm{p}}=0.4382, \quad R=37.049 \mathrm{~m}, \quad \rho=$ $1.225 \mathrm{~kg} / \mathrm{m}^{3}, H_{\mathrm{t}}=1 \mathrm{~s}$

3) Generator of DFIG

Stator resistance $R_{\mathrm{s}}=0.00462$

Mutual inductance $L_{\mathrm{m}}=4.348$

Stator self-inductance $L_{\mathrm{ss}}=4.450$

Rotor self-inductance $L_{\mathrm{rr}}=4.459$

Rotor resistance $R_{\mathrm{r}}=0.006007$

Inertia constant $H_{\mathrm{g}}=0.5 \mathrm{~s}$

4) Converter

$C=0.11 \mathrm{~F}, v_{\mathrm{DC}}=1.5 \mathrm{kV}, L_{\mathrm{g}}=0.3, R_{\mathrm{g}}=0.003$

5) Control parameter

$K_{\mathrm{p} 1}=0.5, T_{i 1}=2, K_{\mathrm{p} 2}=0.0025, T_{i 2}=0.005, K_{\mathrm{p} 3}=$ $0.5, T_{i 3}=2, K_{\mathrm{p} 4}=1.5, T_{i 4}=0.075, K_{\mathrm{p} 5}=1, T_{i 5}=0.02$

\section{References}

[1] Padiyar KR (2002) Power system dynamics: stability and control. BS Publications, Dundas

[2] Subsynchronous Resonance Working Group of the System Dynamic Performance Subcommittee (1992) Reader's guide to subsynchronous resonance. IEEE Trans Power Syst 7(1):150-157

[3] Kundur P (1994) Power system stability and control. McGrawHill, New York 
[4] Anderson PM, Agrawal BL, Van Ness JE (1990) Subsynchronous resonance in power system. IEEE Press, New York

[5] Wilkes J, Moccia J (2013) Wind in power: 2012 European statistics. The European Wind Energy Association (EWEA), Brussels

[6] Mokhtari M, Khazaei J, Nazarpour D (2013) Sub-synchronous resonance damping via doubly fed induction generator. Int J Electr Power Energ Syst 53:876-883

[7] Faried SO, Unal I, Rai D et al (2013) Utilizing DFIG-based wind farms for damping subsynchronous resonance in nearby turbinegenerator. IEEE Trans Power Syst 28(1):452-459

[8] Slootweg JG, Kling WL (2003) The impact of large scale wind power generation on power system oscillations. Electr Power Syst Res 67(1):9-20

[9] Muljadi E, Butterfield CP, Parsons B et al (2007) Effect of variable speed wind turbine generator on stability of a weak grid. IEEE Trans Energ Conver 22(1):29-36

[10] Gautam D, Vittal V, Harbour T (2009) Impact of increased penetration of DFIG-based wind turbine generators on transient and small signal stability of power systems. IEEE Trans Power Syst 24(3):1426-1434

[11] Ostadi A, Yazdani A, Varma RK (2009) Modeling and stability analysis of a DFIG-based wind-power generator interfaced with a series-compensated line. IEEE Trans Power Deliver 24(3):1504-1514

[12] Fan LL, Kavasseri R, Miao ZX et al (2010) Modeling of DFIGbased wind farms for SSR analysis. IEEE Trans Power Deliv 25(4):2073-2082

[13] Wang L, Xie X, Jiang Q et al (2014) Investigation of SSR in practical DFIG-based wind farms connected to a series-compensated power system. IEEE Trans Power Syst 30(5):2772-2779

[14] Suriyaarachchi DHR, Annakkage UD, Karawita C et al (2013) A procedure to study sub-synchronous interactions in wind integrated power systems. IEEE Trans Power Syst 28(1):377-384

[15] IEEE Subsynchronous Resonance Task Force of the Dynamic System Performance Working Group, Power System Engineering
Committee (1985) Terms, definition and symbols for subsynchronous oscillation. IEEE Trans Power Appar Syst 104(6): 1326-1334

[16] Wu F, Zhang XP, Godfrey K et al (2007) Small signal stability analysis and optimal control of a wind turbine with doubly fed induction generator. IET Gener Transm Distrib 1(5):751-760

[17] IEEE Subsynchronous Resonance Task Force of the Dynamic System Performance Working Group, Power System Engineering Committee (1977) First benchmark model for computer simulation of subsynchronous resonance. IEEE Trans Power Appar Syst 96(5):1565-1572

Jing LI received the B. Eng degree from Chongqing University, Chongqing, China, in 2009 and M. Eng degree from University of Science and Technology of China, Hefei, China, in 2012. Currently, he is pursuing the Ph.D degree in Electrical Engineering at the University of Birmingham, Birmingham, UK. His research interests include renewable energy and power system stability.

Xiao-Ping ZHANG is currently a Professor of Electrical Power Systems at the University of Birmingham, UK and he is also Director of Smart Grid, Birmingham Energy Institute. Before joining the University of Birmingham, he was an Associate Professor at the University of Warwick, England, UK. From 1998 to 1999 he was visiting UMIST. From 1999 to 2000 he was an Alexander-vonHumboldt Research Fellow with the University of Dortmund, Germany. He worked at China State Grid EPRI (NARI Group) on EMS/DMS advanced application software research and development between 1993 and 1998. He received the BEng, MSc and Ph.D degrees in Electrical Engineering from Southeast University, China in 1988, 1990, 1993, respectively. He is the co-author of the 1st and 2nd edition of the monograph "Flexible AC Transmission Systems: Modeling and Control", published by Springer in 2006, 2012, respectively. 